\title{
EL CONCEPTO DE BUENA ESCUELA EN APODERADOS CUYOS HIJOS ASISTEN A ESCUELAS DE BAJO RENDIMIENTO EN CHILE ${ }^{1}$ : UN ANÁLISIS ANTROPOLÓGICO-ESTRUCTURAL
}

Javier CORVALÁN $\mathbf{R}^{2}$.

\section{Resumen}

A partir de entrevistas a apoderados que envían sus hijos a escuelas de bajo rendimiento crónico en Santiago se analiza el discurso relativo al porqué de esa conducta, apuntando a las valoraciones que hacen de esos colegios. La investigación parte de otros estudios previos que indicaron una fuerte conformidad de los apoderados en estos establecimientos y su baja disposición al cambio. La metodología utilizada es el análisis estructural de contenido. Se concluye que tanto la valoración del establecimiento como el concepto de una buena escuela para estos apoderados tienen poca relación con aquello que indica el discurso oficial de los poderes públicos al respecto.

Palabras claves: Educación, Chile, escuela de bajo rendimiento, análisis estructural de contenido, investigación cualitativa.

\begin{abstract}
From interviews with the parents who send their children to low performance schools in Santiago it is analyzed the speech related to the reason of that behaviour, pointing out the schools evaluations. The research starts from other previous studies that showed parents strong resignation in these schools and their low willingness to change. The methodology used is the structural analysis of content. It is concluded that the school evaluation and the concept of good quality school for these parents has little connection with what is mentioned in the public authorities' official speech regarding this issue.
\end{abstract}

Key words: Education, Chile, low performance schools, structural analysis of content, qualitative research.

\footnotetext{
Résumé

À partir d'entretiens de parents d'enfants scolarisés dans des établissements au rendement scolaire structurellement faible, l'article analyse le discours de ces acteurs quant aux raisons de leur conduite, en se penchant plus particulièrement sur les jugements qu'ils portent sur ces

${ }^{1}$ Investigación financiada por el Centro de Estudios de Políticas y Prácticas en Educación (CEPPE), Proyecto CIE01-CONICYT como parte de la línea Políticas Educativa, sublínea Mercados educativos en condiciones de pobreza en Chile.

${ }^{2}$ Doctor en sociología. Académico de la Facultad de Educación de la Universidad Alberto Hurtado. Erasmo Escala 1825. Santiago, Chile. Correo electrónico: jcorvala@cide.cl
}

Fecha de recepción del artículo: Junio 2013

Fecha de evaluación: Octubre 2013 
écoles. La recherche s'appuie sur des études antérieures, indiquant la forte adhésion des parents à leur école et, par conséquent, leur faible disposition au changement d'établissement. La méthodologie utilisée est l'analyse structurale de contenu. On aboutit à la conclusion que tant le jugement porté sur l'école que le concept de " bonne école » pour ces parents n'ont que très peu à voir avec ce qu indique le discours des pouvoirs publics à cet égard.

Mots clés : Éducation, Chili, écoles au rendement faible, analyse structurale de contenu, recherche qualitative.

\section{IMPORTANCIA DEL PROBLEMA ESTUDIADO}

El estado de la educación es uno de los aspectos más problemáticos de la sociedad chilena actual y ha sido objeto de intensas disputas académicas en los últimos veinte años, así como de movimientos sociales en el período reciente (Bellei et al. 2010) Diversos análisis han señalado que uno de los problemas críticos de este sistema educacional es su segmentación, en lo que a resultados se refiere (García-Huidobro 2007; Valenzuela et al. 2010).Esto es, que existe una notable diferencia de rendimiento académico entre los colegios dependiendo del nivel socioeconómico de los niños que atiendan. De esta manera, los resultados del rendimiento educacional se correlaciona en Chile fuertemente con un análisis de clase social de origen de los alumnos, lo que se contrapone al ideario democrático que sustenta todo sistema educativo contemporáneo (García Huidobro y Corvalán 2009). A partir de esta constatación y producto de un programa de investigación de varios años en la Facultad de Educación de la Universidad Alberto Hurtado, nos interesó en este artículo analizar parte del discurso de apoderados cuyos hijos asisten a escuelas de bajo rendimiento crónico en Santiago (Chile).Se trata de familias que envían a sus hijos a estas escuelas y que tienen en la cercanía, al menos formalmente, colegios de mejor rendimiento preguntándonos el porqué de esta conducta, es decir, abordando el discurso justificador de la misma.

Lo anterior es particularmente relevante en un contexto como el chileno debido a que su sistema educacional fue bruscamente transformado en la década de los 80 hasta convertirlo en un mercado educativo altamente competitivo en el cual el Estado provee un indicador público y comparativo (SIMCE) del rendimiento promedio de los colegios (Corvalán 2013). Parte de los estudios del programa de investigaciones antes referido determinó que durante largo tiempo ha habido colegios de rendimiento permanentemente bajo, que se encuentran en entornos con colegios de alternativa para las familias que son de mejor rendimiento SIMCE y que no necesariamente los primeros han perdido matrícula de manera significativa (Corvalán y Román 2012).

Al mismo tiempo, se pudo determinar que parte importante de las familias que envían sus hijos a estos colegios mantienen, paradojalmente, una importante conformidad hacia ellos, lo que explicaría su inacción en términos de abandono de tales establecimientos (Corvalán y Joiko 2010; Corvalán y Román 2012). Todo lo anterior nos remite al problema que aborda este artículo: el concepto de calidad de educación y/o de buena escuela que expresan las familias, considerando que, por lo dicho anteriormente, este parece no corresponderse, con aquel de la política educativa oficial en el país (nivel de puntaje SIMCE de cada colegio). De ahí entonces que se realizó una indagación cualitativa entrevistando a 12 apoderados de 6 de estas escuelas (2 por establecimiento) en Santiago y abordando diversos temas concernientes al mencionado programa de investigación. Lo que se expone a continuación es el análisis del problema ya señalado por medio del método que explicamos en el acápite siguiente. 


\section{APROXIMACION METODOLÓGICA}

La metodología empleada en este artículo corresponde al análisis estructural de contenido, que puede enmarcarse en una aproximación cualitativa a datos textuales, proveniente de la tradición de estudios lingüísticos y socio-antropológicos, específicamente de corriente franco-europea. Esta aproximación puede ser entendida también, como parte de un proyecto mayor de formalización y estandarización de procedimientos de análisis cualitativos, que tiene su contraparte en América del Norte en torno a la etnociencia o antropología cognitiva (D`Andrade 1995) y que también toma su base conceptual y epistemológica de la lingüística (en particular, la de tipo estructural). A su vez, este conjunto de procedimientos puede ser considerados en lo que gruesamente se conoce como análisis de discurso desde una problematización no estrictamente lingüística, es decir, un proyecto que trata de estudiar, mediante procedimientos formales, la manera en que lo social se refleja en categorías lingüísticas (Larraín 2010: 29-55). La línea de análisis que aquí ocupamos forma una continuidad de pensamiento, con variaciones, críticas y creaciones durante el siglo XX, que va desde De Saussure (1945) y su aporte respecto de factor performativo y denotativo del lenguaje en tanto estructura de sujeción del hablante, pasando por los aportes de Trubetzkoy (1973), con su perspectiva de análisis basada en oposiciones y en la noción de sistema (a partir también de una lingüística estructural) con su influencia en Lévy-Strauss (1974) que concibe las estructuras socio culturales como comunicación lingüística y a la lingüística estructural como su método de análisis, con el aporte gravitante de Greimas (1971) y Barthes (1971), con el desarrollo contemporáneo de la semántica y la semiología y con la variantes sociológicas de Bourdieu (2002) que ve en el lenguaje una forma tanto de capital como de dominación social, entre otros teóricos que no tenemos el espacio suficiente para nombrar y reconocer. A continuación nos referiremos a los principales aspectos epistémico-metodológicos implícitos en esta perspectiva de análisis.

Es una aproximación estructuralista: en tanto paradigma de las ciencias humanas, el estructuralismo ha ocupado gran parte de la epistemología de aquellas en, por lo menos, la mitad del siglo XX y sus rasgos son reconocibles incluso en autores anteriores a su denominación misma como paradigma (Marx y Durkheim son notables ejemplos). Sepultado y considerado superado en numerosas ocasiones, el estructuralismo parece vigente en la existencia misma de las ciencias sociales y de explicaciones de lo social que se niegan a reducirlo tanto a la sumatoria de la acción individual como a la acción de los individuos sin consideración de un contexto que total o parcialmente les determine (Hughes y Sharrock 1999). En contrapartida a esto último, el análisis estructural de contenido considera que el lenguaje y en particular aquellos actos lingüísticos que son identificables en estructuras de oposición o disyunciones, dan cuenta de totalidades que a nivel de procesos no conscientes determinan el pensar y actuar de los individuos, no como tales, sino como partes de colectivos estructurados. En la cadena histórica de autores que mencionamos en el párrafo anterior esto se refleja en el concepto de lenguaje (dicotomizado en lengua y habla) en De Saussure (1945) hasta el concepto de habitus (como estructura estructurante), en Bourdieu (1972). En consecuencia, la unidad de análisis que vamos a considerar en este artículo no son individuos sino estructuras de su discurso, referidas al problema de investigación que aquí nos atañe, que se reflejan en sus expresiones verbales y que determinan, ya sea como condicionantes de su acción, valoración y/o legitimación, la representación que tienen de una realidad (Ruquoy 1990:95). Un último aspecto a mencionar es que en la tradición estructuralista lo simbólico constituye un elemento central tanto en la explicación de lo lingüístico-social como, en consecuencia, en el objetivo general del proceso de indagación. Esto significa que los seres humanos son entidades lingüístico-simbólicas capaces de construir aparatos denotativos y connotativos de la realidad los que, a su vez, tienen características arbitrarias. Llegar a establecer cuál es la estructura y la combinatoria de tal simbología es la finalidad de todo análisis basado en la epistemología estructuralista (Lévy Strauss 1974). 
El lenguaje no solamente construye la realidad social, sino que la denota: en esta aproximación metodológica no existe una separación formal y observable empíricamente entre una realidad social y una lingüística. Incluso la práctica (praxis), como objeto de estudio sociológico así como los objetos, imágenes, etc, deben ser verbalizados para ser tenidos en cuenta como objeto de observación. El lenguaje también es estructura que sirve no solo para interpretar la realidad (dentro de sus marcos estructurales), sino también para ordenar e incluso (según algunos autores) para estructurar el pensamiento. De ahí entonces que para las ciencias sociales, cuyo objeto de estudio es la constitución de lo que se entienda por realidad social, pasa a ser determinante la captación de información lingüística respecto de la interpretación, la denotación y la praxis social como también su análisis mediante procedimientos que se basan en la estructuración lingüística de esa realidad social. Por lo tanto y siguiendo la tradición de la lingüística y de las ciencias sociales estructuralistas, tanto el método como la constitución del objeto, se superponen (Bourdieu 2005: 51-80).

Lógica de oposición, totalidad, contraste y relacional: Desde De Saussure a Bourdieu el programa estructuralista considera la binaridad con un principio de oposición, como la base, tanto de la constitución de lo real como del método que la investiga. En síntesis, esto consiste en afirmar que el principio de oposición entre dos elementos (binaridad o disyunción) es la base de ordenamiento de la realidad colectiva: conocemos y connotamos la categoría "hombre" porque se opone a otra "mujer". Apoyándonos en el ejemplo anterior, las categorías "hombre" y "mujer" al mismo tiempo que se oponen necesitan, para oponerse, relacionarse con una totalidad ya que toda oposición precisa de un código que la constituya como tal. Esto es lo que en el análisis estructural de contenido se conoce como principio de totalidad o bien, el código propiamente tal, que en el caso del ejemplo anterior sería "seres humanos", con sus componentes de "hombre "y "mujer" incluidos. Se observa entonces que los términos que forman cada código están relacionados por oposición, lo que es una de las bases de todo análisis estructural, en palabras de Bourdieu, "lo real es relacional" (Bourdieu 2007:13). Lo anteriormente expuesto nos conduce a la síntesis del método utilizado que sigue el camino de descubrir binaridades (disyunciones), develar la totalidad a la cual pertenecen (su eje semántico, dando cuenta así del código en cuestión) y establecer, de ser posible, tanto la estructura más amplia de oposiciones con la cual se relacionan como también las valorizaciones y jerarquizaciones de sus elementos constituyentes

Énfasis formalizador:El sustrato lingüístico-estructural del método utilizado es tributario de la tradición formalizadora de análisis de datos textuales o cualitativos como se le conoce en el campo de las ciencias sociales. Con De Saussure la lingüística da un enorme paso desde un saber anclado en las humanidades hacia una disciplina autónoma con teoría y métodos propios y con un énfasis formalizador en sus postulados teóricos que, lejos de aminorarlos, durante el siglo XX los aumenta de manera notable. Por formalización entendemos aquí a un conjunto estable de reglas de procedimientos utilizadas para denotar, connotar y analizar un fenómeno y que se expresan en un meta-lenguaje abstracto, siendo la lógica y la matemática los mejores ejemplos al respecto. La formalización implica un proyecto de universalización de procesos de análisis y de reemplazo del lenguaje literario, dada su ambigüedad y relatividad, por uno de simbología precisa (ver los argumentos al respecto de Boudon 1971:7 y 1991:22). De ahí entonces que el proyecto de formalización de algunas ciencias sociales se traduzca en la matematización de sus postulados (la economía es actualmente el mejor ejemplo). La formalización, además, tiende a cumplir con uno de los objetivos más amplios de la constitución de disciplinas científicas (y no solo del programa positivista de ellas), cual es la vinculación estrecha entre teoría y método y la constitución de ambas en procedimientos genéricos y por lo tanto aplicables a fenómenos diversos. 


\section{CORPUS ANALIZADO}

Como ya señalamos, el origen del corpus analizado en este estudio está dado por 12 entrevistas a apoderados (la mayoría madres) de niños que asisten en total a seis escuelas de bajo rendimiento crónico en Santiago. Se trata de establecimientos ubicados todos en áreas urbanas de bajo nivel socioeconómico y en entornos con colegios de alternativa, varios de los cuales tienen mejor rendimiento SIMCE. De las entrevistas transcritas extrajimos, para efectos del análisis, los párrafos que dicen relación con los siguientes tópicos: i) conceptos de una escuela de buena o mala calidad; ii) razones por las cuales eligieron o llegaron y/o permanecen en esas escuelas; y iii) razones por las cuales cambiarían a sus hijos de escuelas y hacia qué tipo de establecimiento lo harían. El corpus en cuestión constó de 20 páginas y el análisis se hizo siguiendo los procedimientos tradicionales del método escogido, es decir: a) establecimiento de disyunciones $b$ ) identificación de códigos (totalidades) y/o hipótesis respecto a oposiciones no manifestadas; c) identificación de valorizaciones y jeraquizaciones; d) establecimiento de estructuras (paralelas, subordinadas y cruzadas, por motivos de espacio y conceptuales no incluimos los análisis con la llamada estructura o relato de búsqueda); y d) condensación del material $^{3}$; y d) establecimiento de proposiciones conclusivas. En lo que sigue analizamos los materiales que consideramos más ilustrativos para ayudar a responder las preguntas centrales del estudio.

\section{RESULTADOS}

A continuación exponemos un total de 10 extractos de las entrevistas realizadas, a los que denominamos materialesy que se refieren a los párrafos en que los entrevistados se refieren al objeto de investigación. Después de cada material exponemos el análisis que es posible realizar y a medida que estos avanzan damos cuenta de las eventuales relaciones entre ellos. A partir de lo acordado con los entrevistados se utilizan nombres e identificaciones ficticias para preservar su anonimato. Para mostrar estos análisis utilizamos la simbología tradicional del análisis estructural, es decir:

/ : Da cuenta de una relación de oposición entre dos términos o inversos

: Da cuenta de una relación de continuidad semántica entre términos. Constituye lo que Piret et al (1996) denominan doble implicación lógica y que otros autores denominan relación de calificación (Hiernaux 1977).

$+\quad$ : Expresa una valorización positiva del término analizado inferida a partir del discurso del entrevistado.

- : Expresa una valorización negativa del término analizado inferida a partir del discurso del entrevistado.

Eje semántico: En letra destacada se escribe lo que consideramos el eje semántico o totalidad que relaciona la disyunción.

\footnotetext{
${ }^{3} \mathrm{El} \mathrm{término} \mathrm{condensación} \mathrm{se} \mathrm{utiliza} \mathrm{en} \mathrm{análisis} \mathrm{estructural} \mathrm{para} \mathrm{denominar} \mathrm{varias} \mathrm{disyunciones} \mathrm{que} \mathrm{pueden}$ ser sintetizadas en una sola, ya sea la originalmente expresada por el locutor o bien una nueva y que a juicio del investigador da cuenta del concepto base del sujeto, respecto al tema en cuestión (ver Hiernaux 1977: 18 y Piret et al 1996 p:39).
} 
( ): Expresa un término hipotético deducido por el término explicitado por el entrevistado.

\section{Material 1:}

P"¿Cuáles son las razones por las cuales usted eligió este colegio?

R: Por la educación, los profesores que tienen comunicación con los apoderados. Porque yo al mayor lo tenía en otro colegio, particular subvencionado y no me gustó el trato con los profesores, el trato con los directores, no. Lo cambié aquí. y no me gustaba el colegio (anterior), le encontraba otro perfil" (Angélica, colegio 1, entrevista realizada el 6 de octubre de 2010).

En este material identificamos tres disyunciones vinculadas a nuestro problema de investigación: i) la calidad de la educación impartida por el colegio; ii) La calidad de la comunicación con los profesores del colegio; y iii) La calidad del trato con profesores y directores. Estas disyunciones nos permiten establecer una estructura paralela con claras valorizaciones:

\section{(Calidad de la educación impartida por un colegio)}
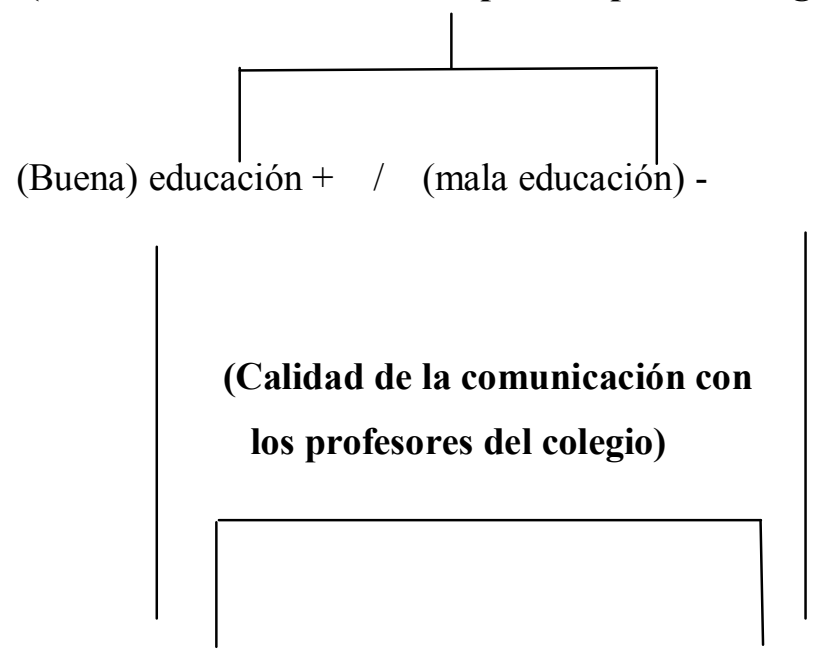
(Buena) comunicación de los profesores
/ (mala comunicación de los
con los apoderados + profesores con los apoderados) -

\section{Calidad del trato con profesores y directores}

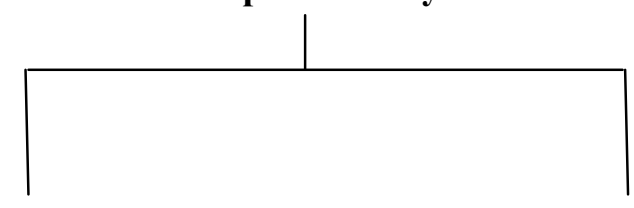

(Buen) trato con profesores y

/ (Mal trato con profesores

directores) +

$$
\text { y directores) - }
$$

Se observa que el código disyuntivo inicial permite condensar a los dos siguientes ya que estos solo son especificaciones de aquel: la calidad del colegio está conceptualizada por el entrevistado con aspectos vinculados a las relaciones humanas y que, en consecuencia, la valorización del discurso es evidente. 


\section{Material 2:}

$\mathrm{P}:$ ¿” Pensó en cambiarlos de colegio?

R: No.

$\mathrm{P}:$ ¿Por qué?

R:Por lo mismo, por la educación, los profesores.

$\mathrm{P}:$ ¿Cómo considera usted este colegio?

Para mí es bueno. Los alumnos (...), bueno, como en todos lados son los que hacen el colegio(...), pero es buen colegio, para mí es buen colegio. El niño que quiere estudiar va a estudiar en cualquier colegio, malo, bueno. Pero para mí éste es bueno, en comparación al colegio en el que estuvo el mayor, es bueno". (Paula, colegio 2, entrevista realizada el 14 de octubre 2010)

En este material identificamos dos códigos disyuntivos: i) la valoración del colegio y ii) el tipo de niño en relación al logro escolar. Las oposiciones binarias de cada código no pueden ser ubicadas una sola estructura paralela dado que no muestran continuidad semántica lineal (o paralela), es decir, de acuerdo a la estructura del discurso en cuestión un niño podría querer estudiar en un buen o mal colegio (dado que no existe doble implicación en los términos opuestos de dos o más disyunciones continuas en un mismo discurso como lo plantea Piret et al 1996:48), lo que de acuerdo a la reglas del análisis de contenido permite formar una estructura cruzada, en este caso con valorizaciones:

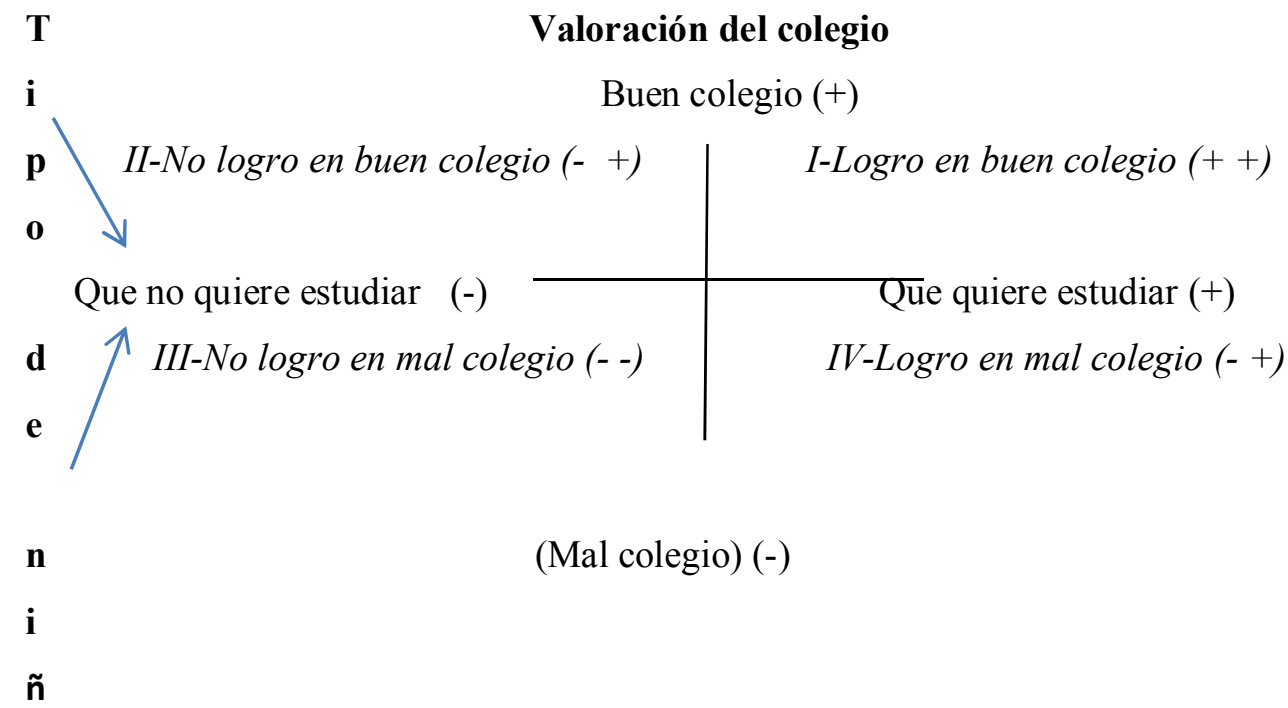

o 
Como todo esquema cruzado con códigos valorizados, éste entrega cuatro realidades fecundadas ${ }^{4}$ (o lógicamente posibles), una categoría plenamente positiva, dos semipositivas (o bien seminegativas, según como se les considere) y una plenamente negativa, es decir, totalmente positiva (tipo ideal puro): la asistencia de un niño que quiere estudiar a un buen colegio; semipositiva 1: la asistencia de un niño que no quiere estudiar a un buen colegio; semipositiva 2: la asistencia de un niño que quiere estudiar a un mal colegio y totalmente negativa (tipo negativo puro): la asistencia de un niño que no quiere estudiar a un mal colegio. Este esquema, permite ordenar el inicio y fin de la cadena de valorizaciones pero deja abierta la pregunta respecto de una eventual jerarquización entre las dos categorías semipositivas, es decir, ¿qué es preferible desde el punto de vista del entrevistado, la asistencia y logro académico de un niño que no quiere estudiar en un buen colegio o la asistencia de un niño que sí quiere estudiar y su logro académico aun cuando sea en un mal colegio? Esta pregunta respecto de valoraciones y jerarquización en dos de los campos o realidades fecundadas se repite obviamente en las estructuras cruzadas mostradas más adelante, por lo que omitiremos esa parte del análisis. Lo que se propone en esta estructura es concordante con lo encontrado en el material 3, analizado a continuación.

\section{Material 3:}

P:"¿Y usted tenía algún conocimiento respecto de cómo era este colegio?

R: Este colegio no está muy bien conceptuado... lo que pasa es que uno tiene que (tener en cuenta) la formación tanto de la escuela como de la casa, total al final uno igual ayudando al niño el niño va a salir adelante, porque igual a mi hijo le ha ido súper bien en el curso, igual tiene promedio seis (coma) cinco. Pero estoy bien conforme en todo caso con el colegio".(Claudio, colegio 3, entrevista realizada el 18 de octubre de 2010).

En el caso de este material se presentan las mismas posibilidades de análisis que para el material anterior, con los códigos de conceptualización del colegio y de tipos de niños en relación a la ayuda en la casa. El resultado es el siguiente:

\footnotetext{
${ }^{4}$ De esta manera denomina Piret et al (1996) los resultados de cada campo en el esquema cruzado como posibilidades lógicas a partir de las oposiciones que se han hecho a partir de las disyunciones confrontadas (ver Corvalán: 2012).
} 
$\mathbf{T}$

i

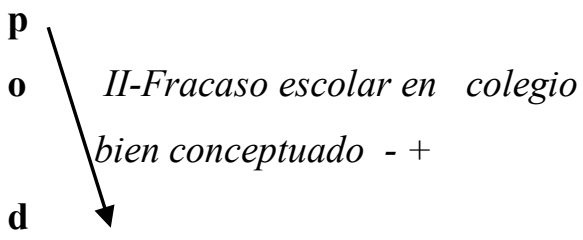

Niño sin ayuda en casa -

$\mathbf{n}$
$\mathbf{i}$
$\tilde{\mathbf{n}}$$\overbrace{\text { III-Fracaso escolar en colegio }}^{\text {mal conceptuado - - }}$

o

(Colegio mal conceptuado) -
I-Éxito escolar en colegio

bien conceptuado ++

$I V$ - Éxito escolar en colegio en

bien conceptuado + -

Dado lo evidente de la continuidad de esta estructura con la propuesta a partir del material 2, con lo que podemos comparar los cuatro elementos generados (uno en cada campo) y las valorizaciones respectivas:

\begin{tabular}{|l|l|ll|}
\hline Ubicación & Material 1 & Material 2 \\
\hline $\begin{array}{l}\text { Alta } \\
\text { valorización } \\
\text { (realidad } \\
\text { ideal): }++\end{array}$ & $\begin{array}{l}\text { Asistencia a un buen colegio de } \\
\text { un niño que quiere estudiar. }\end{array}$ & $\begin{array}{l}\text { Niño que tiene éxito escolar en colegio bien } \\
\text { conceptuado }\end{array}$ \\
\hline $\begin{array}{l}\text { Semi } \\
\text { valorización } \\
1(-+)\end{array}$ & $\begin{array}{l}\text { Asistencia de un niño que no } \\
\text { quiere estudiar a un buen colegio }\end{array}$ & $\begin{array}{l}\text { Fracaso escolar de un niño en colegio bien } \\
\text { en conceptuado }\end{array}$ \\
\hline $\begin{array}{l}\text { Semi } \\
\text { valorización 2 } \\
(+-)\end{array}$ & $\begin{array}{l}\text { Asistencia de un niño que quiere } \\
\text { estudiar a un mal colegio }\end{array}$ & Éxito escolar en colegio mal conceptuado \\
\hline $\begin{array}{l}\text { Bajo o nula } \\
\text { valorización } \\
\text { tipo negativo } \\
\text { puro) }\end{array}$ & $\begin{array}{l}\text { Asistencia de un niño que no } \\
\text { quiere estudiar a un mal colegio }\end{array}$ & $\begin{array}{l}\text { Fracaso escolar en colegio } \\
\text { conceptuado }\end{array}$ & mal \\
\hline
\end{tabular}

El análisis y comparación de los dos materiales anteriores nos indica que para los entrevistados existe por separado el concepto de mal o buen colegio y el de mal o buen alumno, no estando (necesariamente) causalmente relacionados. Como se vio en el primer material y se observará también más adelante, el primer concepto dice relación con características relacionales al interior del establecimiento y el segundo con meritocracia o bien con características psicológicas del niño y/u otras de su ambiente familiar. 


\section{Material 4:}

"Estoy súper bien con el niño. Hago comparaciones con otras amigas que se llevaron a los niños, e incluso (los míos) están más adelantados, porque (los profesores) se dedican cien por ciento a los niños, y eso es lo bueno, eso es lo bueno que tiene el profesor. (El profesor) está con todas las ganas, y (estoy) súper contenta, los niños igual. Además uno tiene que ver donde el niño se sienta bien también, con los profesores y en la casa, en los dos lados". (Isabel, colegio 4, entrevista realizada el 20 de octubre de 2010).

A partir de este material podemos formas nuevamente una estructura paralela con las correspondientes valorizaciones:

\section{Nivel de conformidad con el colegio}

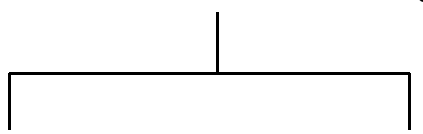

Estar súper bien con el colegio (+) / (Estar disconforme con el colegio) (-)

\section{(Indicador del aprendizaje de los niños)}

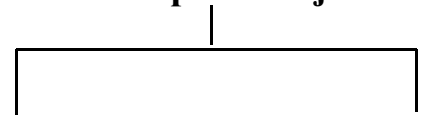

Los niños están más adelantados / / (los niños están más atrasados que los de otros colegios + que los de otros colegios) -

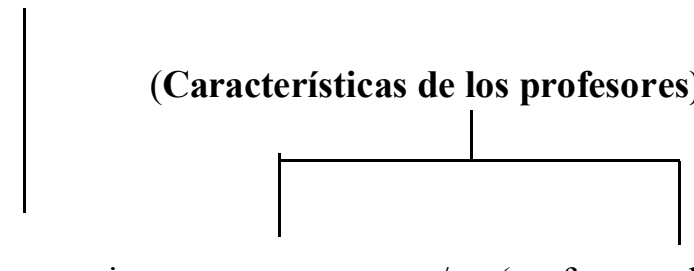

Profesores animosos $+\quad /$ (profesores desganados) -

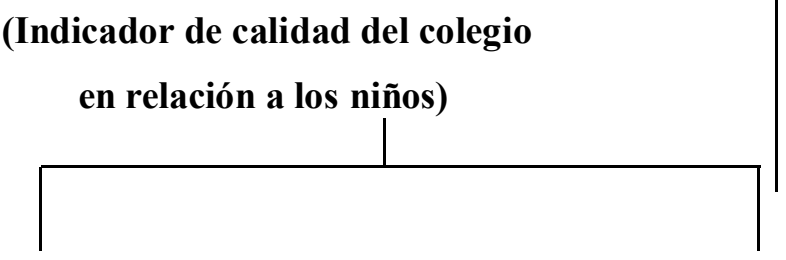

Satisfacción del niño en el

/ (insatisfacción del niño con el colegio) -

colegio + 
Observamos en la estructura paralela anterioruna posibilidad de condensación a partir de la primera de las disyunciones y que aquellas que le siguen especifican los contenidos de la conformidad con el colegio, lo que va desde la comparación del avance de los niños en aprendizaje (que de paso da cuenta de algo central de toda epistemología estructuralista y que mencionamos al principio de este artículo: la construcción de lo real por medio de lo comparativo o relacional) hasta características actitudinales de los profesores y una referencia algo más ambigua respecto de la satisfacción de los niños.

\section{Material 5:}

P:" ¿Cómo considera usted que es el colegio?

R: Mire, respecto a los niños, la educación, sí, más o menos. Pero como le digo... yo estoy conforme con este profesor. Lo que es malo es el ambiente, la gente. Porque hay mucha droga, mucha delincuencia, por eso a veces los apoderados quieren llevarse a los niños para otro lado. Hay niños muy rotos, no tienen una buena formación del hogar, muy sin respeto. Pero eso no es de aquí, es de afuera. O sea, la escuela no puede hacer más...pero debido a eso, a la formación que tienen en la casa, lo malo que viene de afuera hacia acá. No hay respeto".(Mariana, colegio 4, entrevista realizada el 21 de octubre de 2010).

Procedemos a un análisis similar al realizado en el material anterior: 

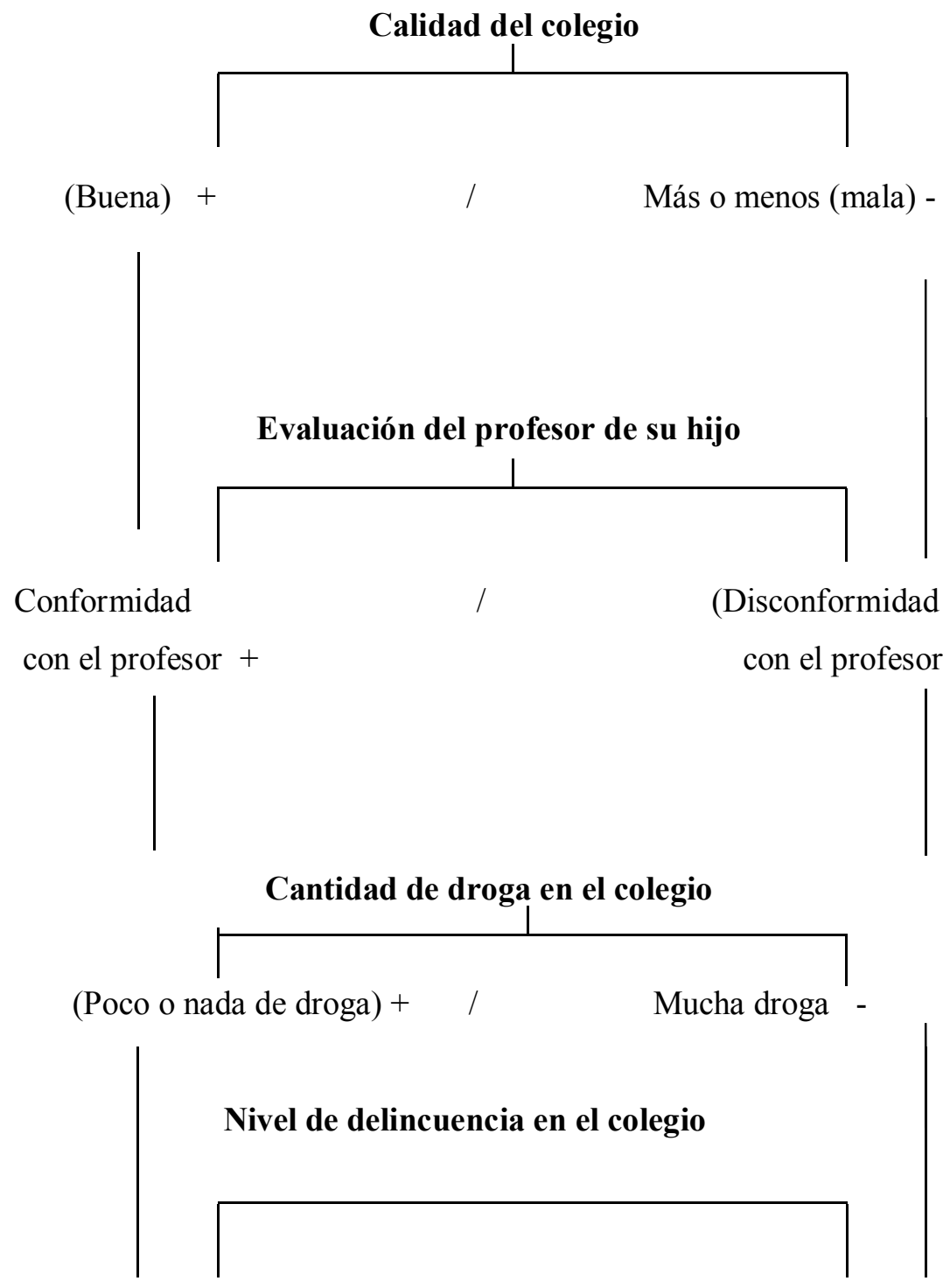

(Poco o nada de delincuencia $)+\quad / \quad$ Mucha delincuencia -

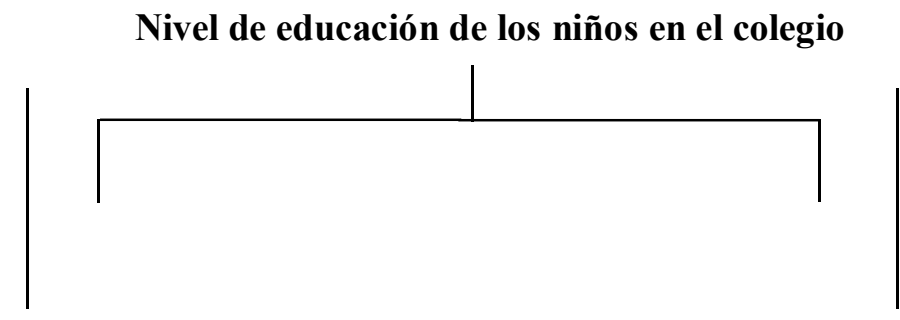

(Niños bien educados) $+\quad / \quad$ Niños muy rotos - 
Tipos de hábitos de las familias del colegio

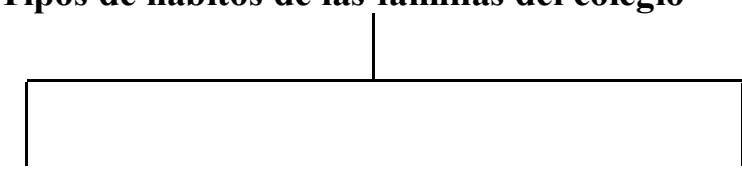

(Familias con buenos hábitos) $+\quad / \quad$ Familias con malos hábitos

\section{Nivel de respeto en el colegio}

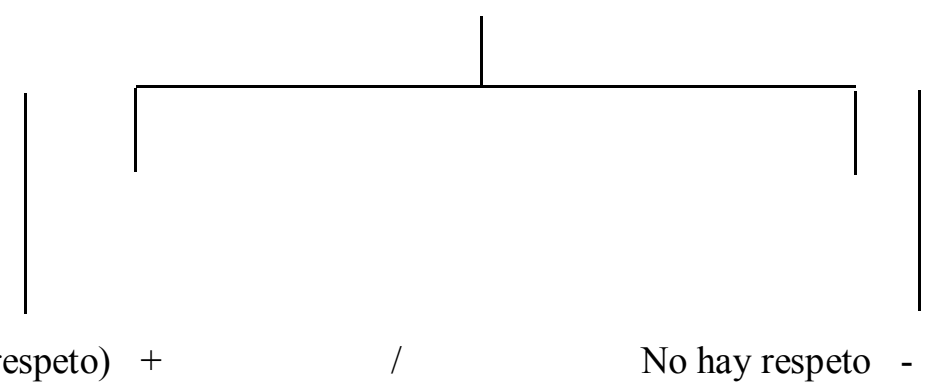

Al igual que en el material anterior en este es posible condensar las disyunciones a partir de la primera de ellas que se refiere a la calidad adjudicada al colegio. Así, las disyunciones posteriores especifican la inicial indicando por un lado la importancia de la conformidad con el profesor del hijo y luego, aludiendo a una serie de características del ambiente social del establecimiento.

\section{Material 6:}

"Yo creo que donde uno coloque al niño, el niño le va a rendir igual. Sale para afuera de aquí de octavo (básico) y el niño que va a estudiar, y va a hacer otra cosa, va a ser igual. Con hartas mamás conversamos y realmente es el ambiente. Pero a la escuela yo no la considero tan mala, porque es acogedora, no hay problemas con los profesores. Por lo menos yo con nadie, con ningún profesor. Y la enseñanza, bueno, si yo dejo a mi niño chico a un lado, yo no me preocupo de él, lo que le enseñen los profesores no más, pero si es uno la que está detrás de los niños. Yo estoy detrás de mi hijo, y mi hijo tiene buenas notas porque yo me preocupo de él. Y aquí la mayoría de las mamás no están ni ahí con los niños, ese es el problema. Entonces si no hay nadie que está apoyando al niño, el niño va a tener problemas en todos lados, hasta en el colegio más caro que lo ponga va a tener problemas". (Cristina, colegio 6, entrevista realizada el 25 de octubre de 2010).

En el material 6 observamos una serie de disyunciones que replican, con otros términos, lo encontrado en las disyunciones anteriores (que, además, pertenecen a otros entrevistados) y que nos permiten formar dos estructuras paralelas con sus correspondientes valorizaciones. La primera estructura puede refiere a las condiciones de éxito escolar del niño: 


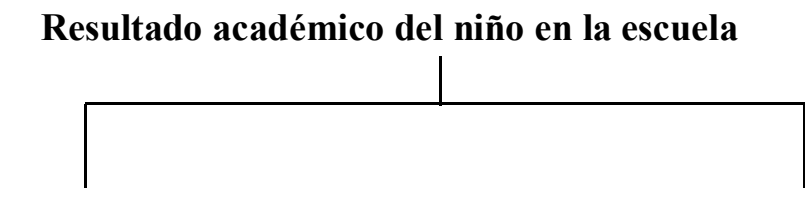

Éxito escolar del niño $+\quad / \quad$ (No éxito escolar del niño) -

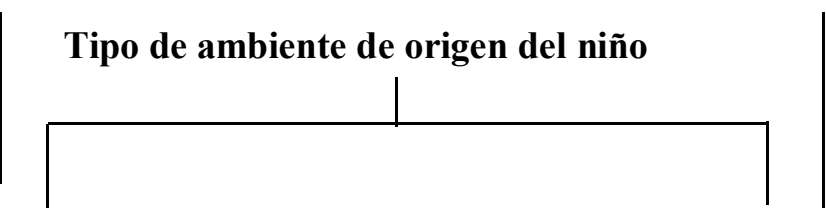

Buen ambiente de origen $+\quad /$ (Mal ambiente de origen $)-$

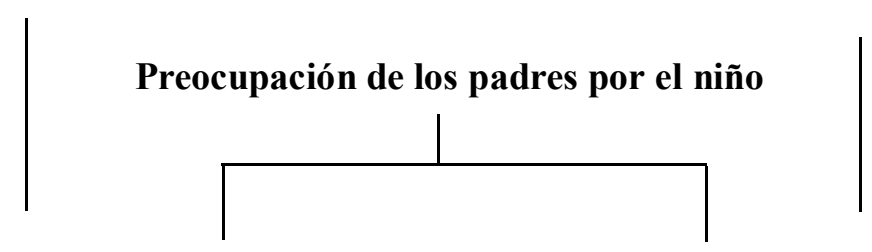

(Padres se preocupan del niño) $+/$ Padres dejan al lado el niño -

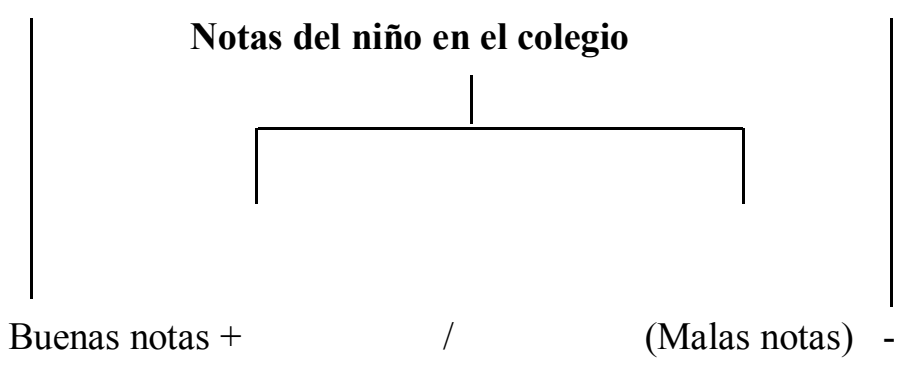

La segunda estructura dice relación con la apreciación de la calidad de la escuela: 

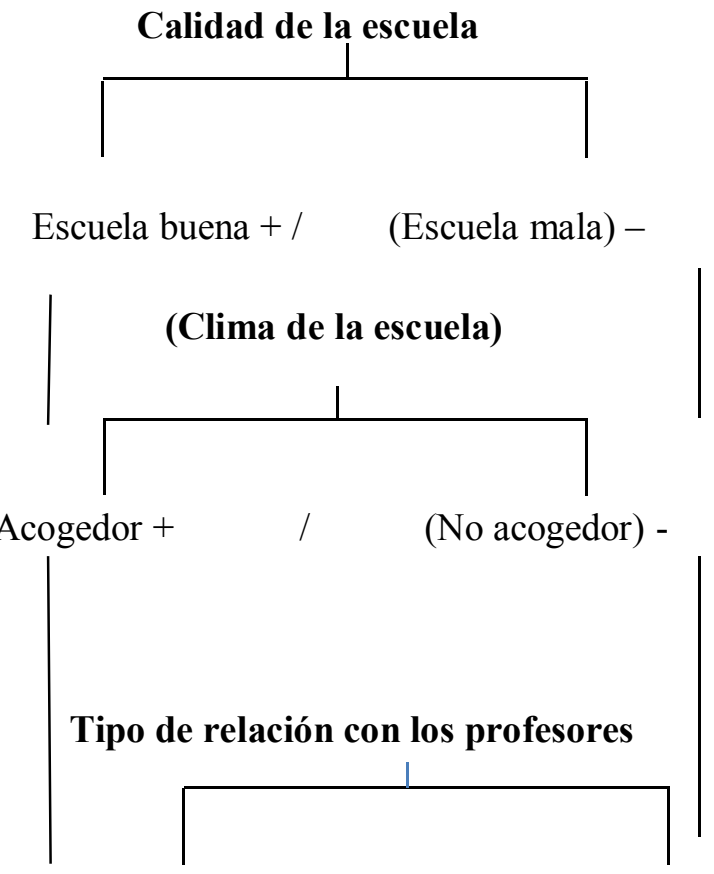

Sin problemas con profesores $+/$ (con problemas con profesores) -

Lo que en definitiva y condensando ambas estructuras paralelas bajo su disyunción inicial, lleva a una estructura cruzada, similar a las ya analizadas cuyos códigos centrales ${ }^{5}$ son tipo o calidad de escuela y resultado escolar dando, dando lugar a los campos siguientes:

${ }^{5}$ De aquí en adelante denominamos códigos centrales a aquellos que engloban o condensan el sentido de las disyunciones que les siguen. 


\section{Calidad de la escuela}

Escuela buena $(+)$

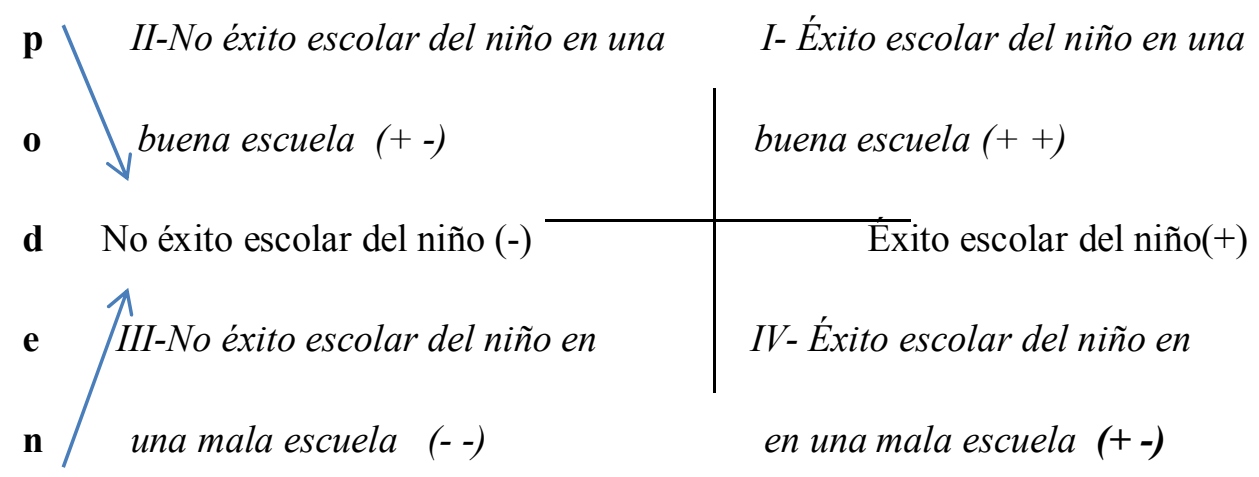

i

Escuela mala (-)

$\tilde{\mathbf{n}}$

o

La conclusión del análisis de este material es similar a lo concluido de los materiales 2 y 3 y refiere a la independencia conceptual del éxito escolar del niño en relación al tipo de escuela, argumentando las razones que ya expusimos en su oportunidad.

\section{Material 7:}

R: “Al principio fue por la cercanía, porque vivimos acá al frente. Pero después se fue dando por la calidad de la educación que tenía y que tiene el colegio, porque han mejorado bastante la educación, tiene excelentes profesores.

P: ¿En qué se ha dado cuenta que ha mejorado la calidad de la educación en el colegio?

R: En los mismos hijos una se da cuenta, porque todos los niños que han salido de octavo (básico), no han tenido ningún problema en enseñanza media, van con una base muy buena. Entonces ahí uno se da cuenta de la calidad de la educación, de la formación, que estando aquí de kínder hasta octavo, les va bien en la educación media, porque la formación de chicos es buena". (Jorge, colegio 2, entrevista realizada el 14 de octubre de 2010).

Este material reafirma parte de los hallazgos anteriores y permite formar una estructura paralela: 


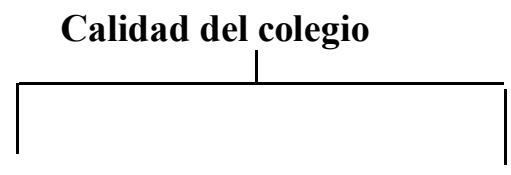

Buen colegio $+\quad / \quad$ (Mal colegio) -

\section{Calidad de los profesores}

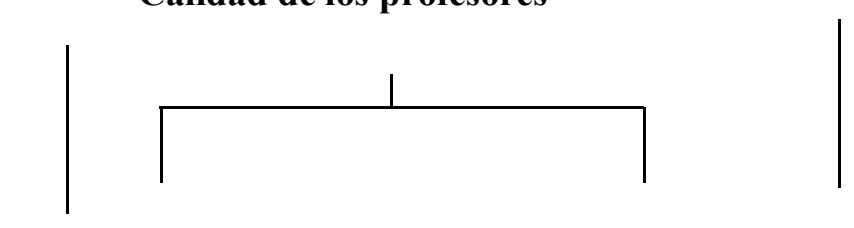

Excelentes profesores + / Malos profesores -

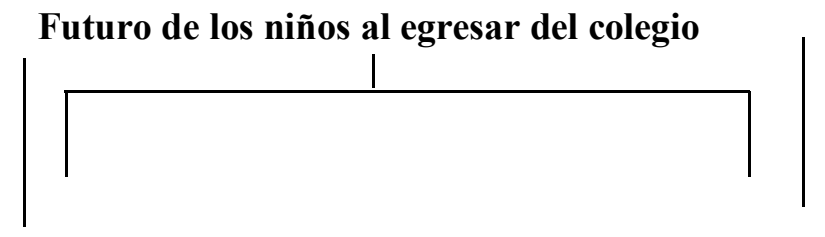

Niños que egresan no
(Niños que egresan si tienen problemas en el liceo) -

El material, por un lado, nos reafirma hallazgos anteriores como la valoración de la escuela a partir del juicio sobre los profesores y, por otro, nos entrega un nuevo elemento de valoración consistente en el desempeño académico posterior de los niños.

\section{Material 8:}

"Yo soy mamá soltera, soy jefa de hogar de ocho hijos, y encontré como apoyo en la parte paterna que les faltaba a mis hijos, lo encontré aquí en el colegio. Yo tengo seis hijos hombres, y ellos están con una buena formación para ser de una mamá sola. Entonces, esa formación se la agradezco a los profesores de este colegio, porque siempre estuvimos solos, sin un apoyo paterno o un hombre que estuviera en la casa. Entonces acá en el colegio, ahí lo encontraron ellos y yo. Primero yo, como madre, encontré la parte paterna que ellos necesitaban y ellos todavía vienen a buscarla, a pesar que no están aquí, igual llegan a buscar al colegio esa parte que les falta. Entonces, por eso yo encuentro que bien, el colegio está bien" (Cecilia, colegio 1, entrevista realizada el 6 de octubre de 2010).

El material anterior admite dos lecturas en cuanto a códigos centrales. La primera es la que aparece en la pregunta inicial del estudioy sería "motivos para asistir a este colegio" la segunda sería más interpretativa pero al mismo tiempo más relacionada con nuestra problemática central en este artículo y nos permite llamar al código: "características de la buena escuela". La solución que proponemos es subordinar el primer código al segundo, de manera de formar lo que en el análisis estructural de contenido se denomina una estructura jerarquizada, y que 
observamos en "términos que tienen el doble estatus de inverso de una disyunción y de eje (semántico) en otra" (Piret et al, p. 42, el paréntesis es nuestro). De esta manera si por un lado un código o eje semántico está constituido por la "calidad de la (una) escuela", este subordina en uno de sus polos otro código que es el "tipo de madre que envía sus hijos" que está polarizado por su situación familiar. La estructura resultante es la siguiente:

\section{Calidad de una escuela}

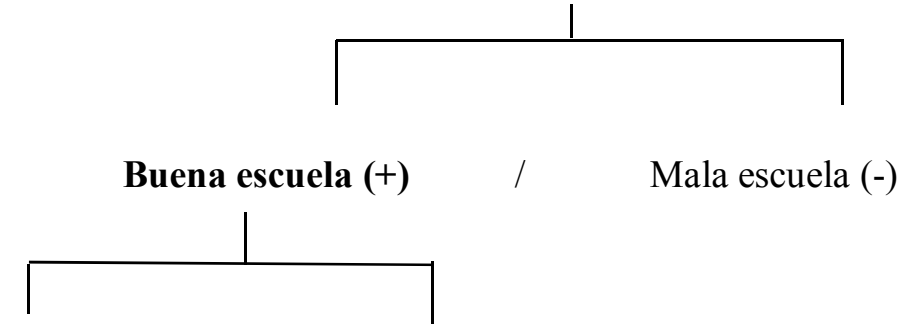

Para una madre soltera / (Para una madre con marido)

\section{Tipo de profesores de la escuela}
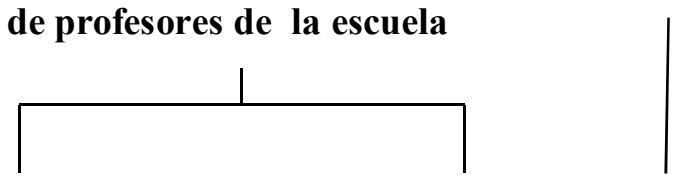

Profesores como figuras paternas $+/$ (Profesores como figuras no paternas) -

Como se observa, este material entrega un elemento nuevo y que podemos denominar la calificación de una escuela como buena a partir del apoyo que da a las familias y a los niños en términos afectivos y de suplencia de figuras familiares.

\section{Material 9:}

R:"A mí siempre me ha gustado este colegio...Porque yo digo que el niño que viene a aprender aprende en cualquier colegio, pagado o no pagado. Y este colegio es bueno, mis hijos han aprendido harto, mi hija no ha repetido ni un curso, el más chiquitito ya le falta un pelito para que aprenda a leer. Así que yo estoy contenta. Estoy conforme con lo que han aprendido ellos, si.

$\mathrm{P}:$ ¿Sabe de la existencia de establecimientos mejores en el sector?

$\mathrm{R}$ :Es que yo nunca he averiguado, ni siquiera he intentado (...) es que mis hijos desde que empezaron a estudiar han estado aquí. No (...) porque me dicen que en los otros colegios hacen pruebas, cosas así, entonces uno (...) no es de miedo a que el niño no dé porque a lo mejor da con la prueba, pero yo estoy acostumbrada aquí, porque conozco a los profesores, al director y nunca he tenido ni un drama, nunca, ni un problema. Yo considero que es bueno (el colegio), mis hijos han aprendido (...) como le digo, el niño que quiere aprender aprende donde sea.

Si ellos (sus hijos) me dijeran a lo mejor (los cambiaría). Pero mi hija nunca me ha dicho que quiere irse, además que tiene todas las amigas aquí, del kínder hasta ahora están con 
las mismas compañeras ahora están en cuarto todas, son las mismas niñas. Entonces vienen de chiquititas con ella y pa que vayan a otro (...) más encima que no se poh, a mí no me gustaría cambiarla... De mi hija yo no me quejo, gracias a Dios va súper bien. Tenía rojos (malas notas) en lenguaje, vino unos días a reforzamiento y lo salvó al tiro. No me quejo con mi hija" (Alejandra, colegio 6, entrevista realizada el 25 de octubre de 2010).

El material anterior reafirma y comienza a saturar la información encontrada hasta el momento. En él encontramos los siguientes códigos centrales: i) Características del niño que tiene éxito escolar; ii) Criterios para evaluar la calidad del colegio de sus hijos (que solo da lugar a una disyunción aislada); y iii) Razones para no intentar cambiarse de colegio. Las tres se relacionan de manera de aportar al objetivo de nuestro estudio.

Respecto del primer código, consideramos que en diferentes partes del material agrupa a tres disyunciones en estructura paralela y que la tercera de ellas puede ordenarse como estructura jerarquizada en torno a las especificaciones de tipos de colegio (en los cuales un niño podría aprender si tiene la voluntad de hacerlo, según la entrevistada):

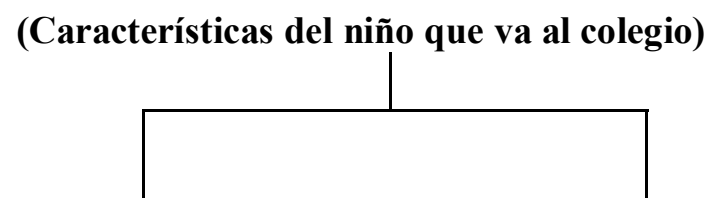

Niño que quiere estudiar $+\quad /$ Niño que no quiere estudiar -

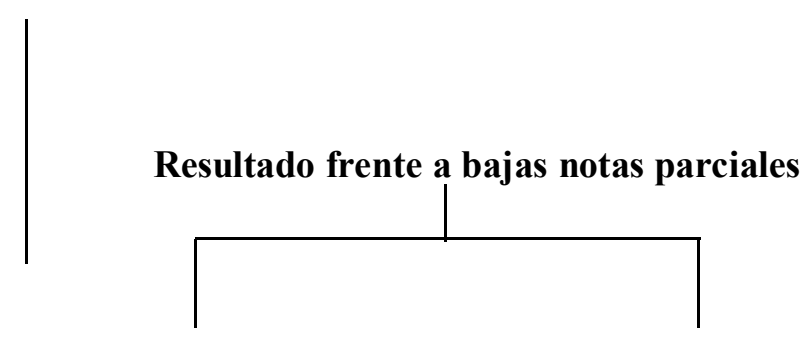

Tener notas rojas y superarlas $+/ \quad$ (Tener notas rojas y no superarlas) -

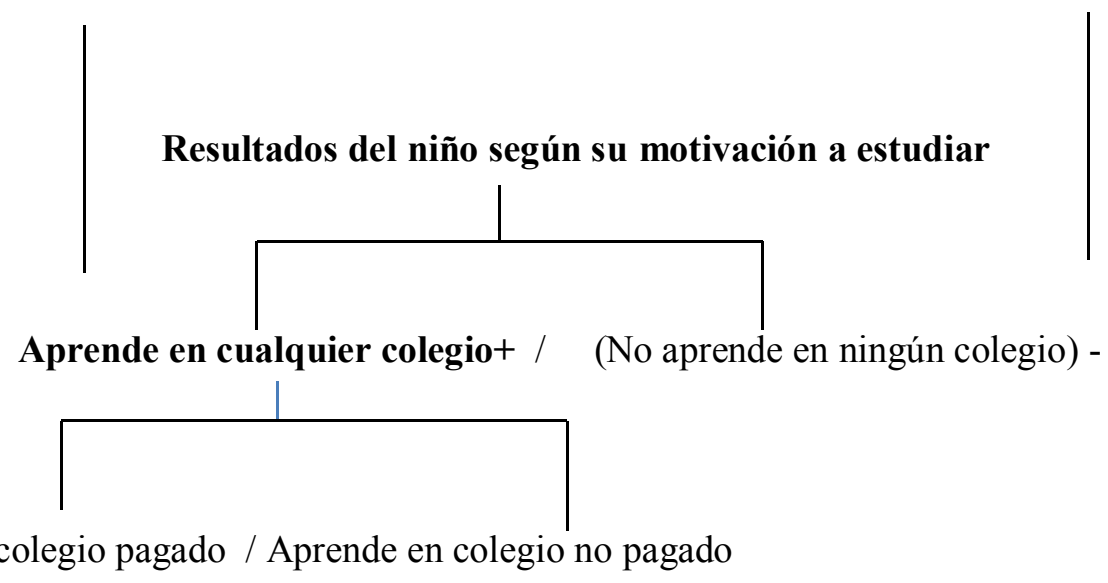


Respecto del segundo código que forma una disyunción aislada:

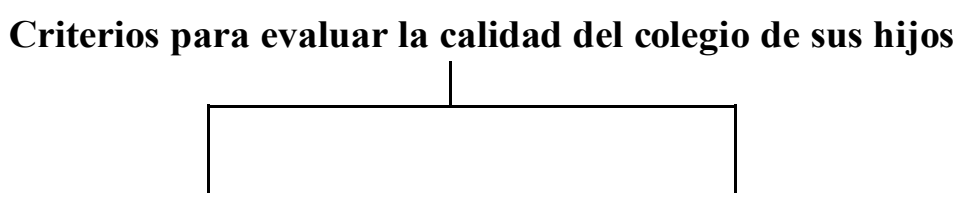

Aprender harto $=$ no repetir $+/$ aprender poco $=$ repetir -

Respecto del tercer código:

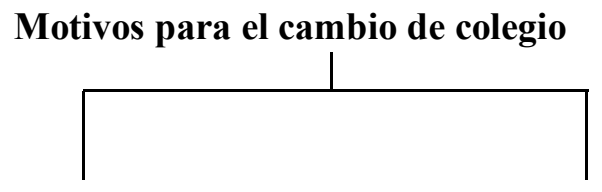

Voluntad del niño para cambiarse + / No voluntad del niño para cambiarse -

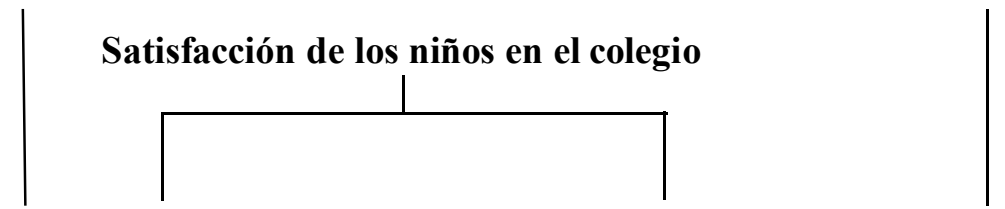

No tener amigos en el colegio $+/$ Tener amigos en el colegio -

\section{Consideraciones para cambiar al hijo de colegio}

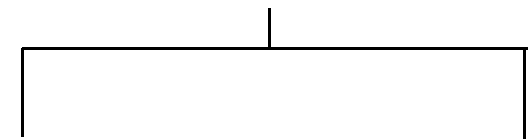

Colegios de alternativa no hacen prueba de / Colegios de alternativa hace pruebas de selección + selección -

El análisis entrega información ya saturada como es el aspecto meritocrático del éxito escolar y otra complementaria como el criterio de la no repitencia como sinónimo de aprendizaje y la consideración de aspectos subjetivos del niño para cambiarlo o no de establecimiento.

\section{Material 10:}

“(Me gusta la escuela) porque... tengo mayor comunicación con los profesores, puedo estar viniendo todos los días... estoy mucho más cerca por cualquier cosa. En el otro colegio que yo la tenía no le dan todas estas facilidades ni el apoyo moral que ella necesitaba (la hija), porque es como más fría la enseñanza, como que no hay tanto calor humano. Acá, se preocupan más por los niños...incluso, hasta los que tienen mala conducta también se preocupan mucho de, y les dan muchas oportunidades. (El colegio) está dentro de lo normal de los colegios, en el medio que vivimos. Hay niños que tienen muy mala conducta que son muy difíciles de controlar, los apoderados no cooperan mucho, con que los apoderados igual se ponen al mismo nivel de los hijos. Yo creo que va a tener muy malas opiniones (de los otros padres sobre el colegio), los apoderados, los mismos que producen todos los problemas acá son los que evalúan el colegio y van a tener muy malas referencias. Yo creo que si una persona observa la situación y todo, y ve de que se ha dado una lucha con este colegio y se está tratando de sacar adelante. Lo que pasa es que cuesta mucho, porque son costumbres, cultura más que nada. Yo creo que lo que aquí más juega en contra es la cultura, porque 
cuesta mucho que la gente vea que es un tremendo edificio, es un establecimiento digno para que los chiquillos. Entonces, va más por un problema de cultura, que la gente no toma conciencia de lo que tiene. (Un buen colegio es) un colegio donde les enseñen más modales. Aquí se los tratan de enseñar, pero es difícil que aquí lo capten. La enseñanza (del colegio) no es mala. Porque es de buenos profesores y la preocupación que ellos les dan. Entonces, la enseñanza no es mala, lo malo es el ambiente, el entorno, los niños que llegan acá, con la cultura y la mentalidad que vienen, es eso lo que echa a perder el colegio, no lo que es la enseñanza es la conducta que echa a perder el sistema acá (...) Hay niños que tienen problemas con la justicia, tienen problemas en el desarrollo de la familia, hay drogas, hay delincuencia. Entonces, hay muchos niños con esos problemas aquí y estos son los niños que contaminan a los niños normales, buenos, que quieren estudiar y su objetivo es estudiar, y contaminan el sistema, ése es el problema que hay en este colegio. (Estoy conforme) en relación a lo que es estudios, sí. Pero lo que es ambiente, no. Y yo creo que es ése el problema más grave que hay, que no haya selección. Porque si hubiese selección, yo creo que sería muy diferente aquí el sistema. Y no se le permite, creo, a los municipales tampoco hacer selección, los colegios municipales dicen que son para todos, pero lo que no dicen que para todos los que quieran estudiar no más. Porque hay muchos que para todos, pero no quieren estudiar y quieren para ocupar el tiempo o los mandan de la casa para que no estén "revolviendo el gallinero" en la casa y no les gustan las reglas ni la disciplina". (Teresa, colegio 3, entrevista realizada el18 de octubre de 2010)

Hemos dejado para el final este material extenso ya que debido a su riqueza sintetiza varios de los hallazgos del estudio. En primer lugar observamos las siguientes códigos centrales: i) Criterios para evaluar el colegio; ii) Causas de la mala evaluación de los apoderados al colegio; iii) Causas del mal ambiente del colegio;iv) Valoración del colegio de acuerdo al ambiente social de la familia y v) Características de un buen colegio. Respecto del primer código central: 


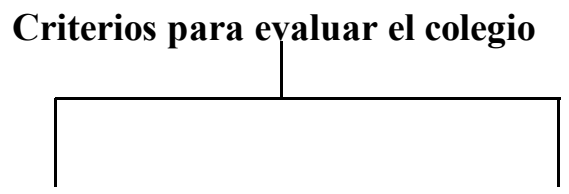

Mayor comunicación con los profesores + / (Menor comunicación con los profesores) -

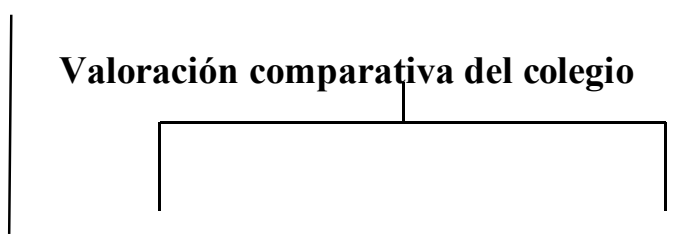

Dentro de los normal, de acuerdo al medio + / (Distinto a lo normal, de acuerdo al medio) -

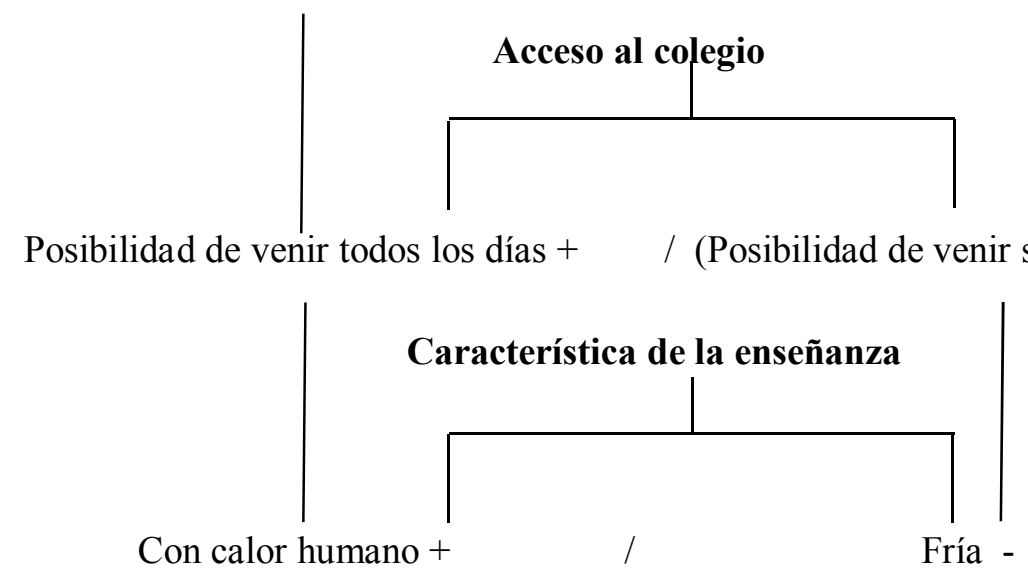

Respecto del código central causas de la mala evaluación de los apoderados al colegio:

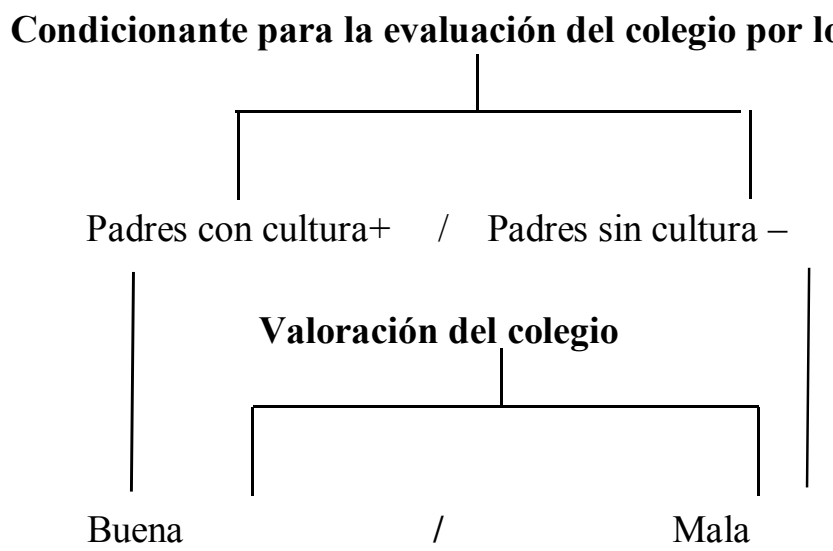

Respecto del código causas del mal ambiente en el colegio: 
Respecto del código causas del mal ambiente en el colegio:

\section{Tipo de apoderados}
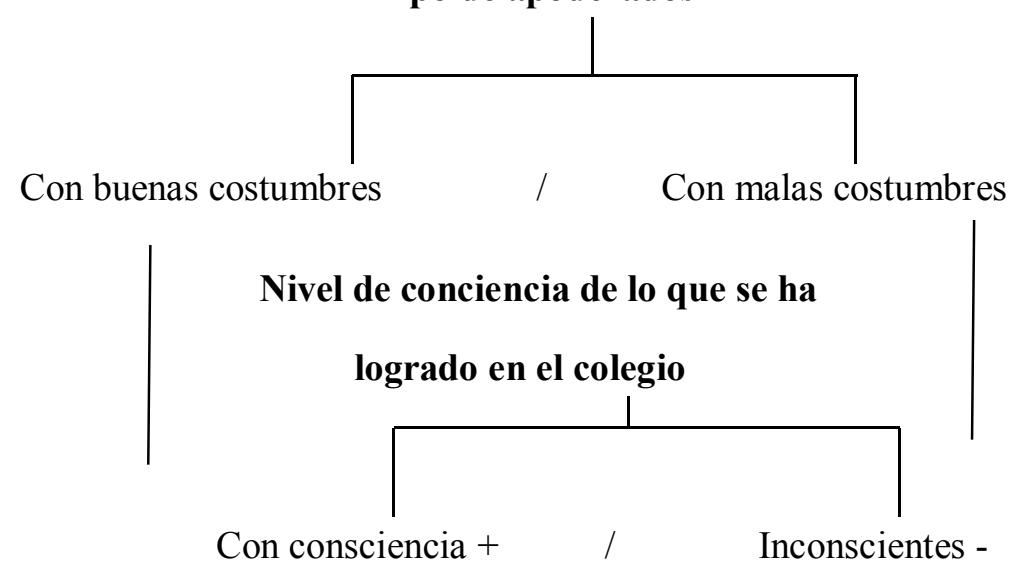

Respecto del código valoración del colegio de acuerdo al ambiente social de la familia se genera una estructura jerarquizada:

\section{Tipos de colegio en relación a su ambiente social}

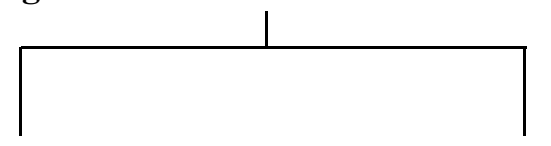

Con selección de alumnos + / Para todos los alumnos -

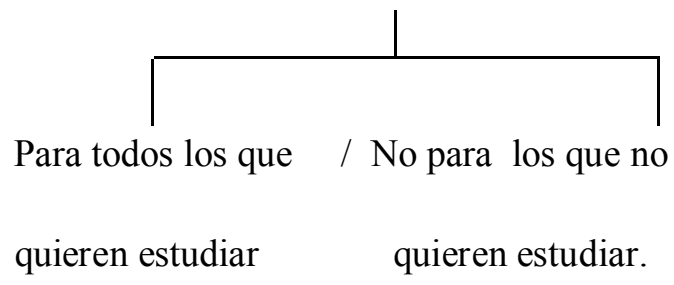

Finalmente respecto del código características del buen colegio:

\section{Criterios para evaluar la calidad de un colegio}

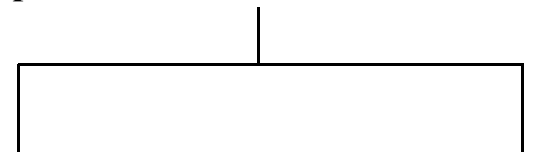

Bueno: donde enseñan (más) modales + / Malo: donde no enseñan modales - 
Como se observa, los códigos y estructuras formadas son recurrentes en la mayor parte de los temas ya vistos en los análisis anteriores y además pueden ser condensados en algunos códigos y disyunciones centrales. El primero (respecto de la evaluación del colegio) reitera el argumento de relaciones humanas matizado con la cercanía al hogar. Respecto del segundo y tercer código ellos pueden ser vistos como complementarios puesto que especifican tipos de padres, jerarquizándolos y atribuyendo en uno de ellos la mala imagen y los problemas del establecimiento, lo que se agudiza dada la no selectividad del colegio en cuanto a las familias que ingresan, estableciendo una oposición entre los niños que quieren y aquellos no lo quieren hacer. Finalmente, el cuarto y quinto código refuerzan los conceptos ya analizados de las estructuras anteriores.

\section{CONCLUSIONES}

Los análisis de los materiales utilizados permiten llegar a dos tipos de conclusiones, respecto de la eficacia del método y respecto de la problemática abordada. Sobre la eficacia del método: i) El método de análisis estructural de contenido nos posibilitó un ordenamiento del proceso y una formalización de sus procedimientos, teniendo en cuenta la relatividad y el problema siempre presente de operacionalización de los datos textuales. De esta manera y como en todo proceso basado en formalización de procedimientos, este es un avance hacia la fiabilidad del análisis cualitativo, es decir, que distintos investigadores analizando los mismos materiales lleguen a similares proposiciones (estructuras), teniendo en cuenta que tal etapa no es el resultado final del estudio, sino uno intermedio. El resultado final, en toda disciplina pero particularmente en las ciencias sociales, es una interpretación de esos análisis intermedios, sean ellos formales o no; ii) Los análisis realizados posibilitaron una rápida saturación de la información siendo recurrentes los contenidos de las estructuras propuestas. Sería interesante en futuros estudios o en el mismo, utilizar otra metodología de análisis cualitativo para observar a que conclusiones se llega y si ellas son distintas o complementarias a las nuestras; y iii) Como en todo análisis de tipo estructural, el problema de la posibilidad de cambio de acción o conducta de los sujetos surge como un importante problema teórico. En efecto, si lo que observamos a partir de su expresión lingüística son estructuras sociales internalizadas en ellos, ¿cómo es entonces posible su transformación? Esta es una pregunta que está presente en este trabajo (y en el proyecto mayor de investigación al cual remite) y que de manera más amplia ha servido de cuestionamiento desde sus inicios al paradigma estructuralista.

Respecto del problema sustantivo en análisis: i) Se observa que los análisis son fuertemente recurrentes y convergentes, en primer lugar, respecto al concepto de la calidad de la educación especificado por lo general en la valoración del colegio al cual asisten sus hijos. Pudimos recoger un conjunto de términos que refieren principalmente a aspectos subjetivos y relacionales, tales como el trato y la comunicación con los profesores y directivos, la acogida de los profesores a los alumnos, etc; ii) En segundo lugar está presente en el discurso de los entrevistados lo que podríamos llamar una lógica individualista y meritocrática del logro escolar de los niños, que independiza su eventual éxito o fracaso académico del tipo de colegio al cual asiste y que alude tanto a características psicológicas "intrínsecas" del niño como a características y conductas de la familia ("apoyo de los padres"). Esto quiere decir que en el discurso analizado el resultado escolar de los niños en escuelas de bajo rendimiento es interpretado de manera independiente a elementos sociales y estructurales del colegio. En esa perspectiva, la eventual movilidad y abandono de la escuela a la cual asisten los niños al momento de la entrevista es algo poco relacionado con la calidad o rendimiento que la política educativa oficial les adjudica (SIMCE); y iii) El análisis realizado demuestra que los códigos culturales que utilizan los sujetos para valorar la educación, cuando ello va más allá de los aspectos subjetivos dice relación con elementos comparativos asociados con aprendizaje, tales 
como la no repitencia, las notas obtenidas, el grado de avance en relación a niños que van a otros colegios y/o el desempeño en enseñanza media cuando este se da en otro establecimiento y que como en el punto anterior, tampoco tienen relación con el discurso de la política oficial al respecto basada en el SIMCE o en indicadores similares.

\section{BIBLIOGRAFÍA}

BARTHES, R(1971). Elementos de semiología - Alberto Corazón editor- México

BELLEI, C, CONTERAS: D y VALENZUELA, J.P(2010).Ecos de la revolución pingüina, Universidad de Chile-UNICEF- Santiago.

BOURDIEU, P (1972). Esquisse d'une théorie de la pratique- Droz- Genève, Paris.

BOURDIEU, P (2002).Questions de sociologie -De Minuit- Paris.

BOURDIEU P, CHAMBOREDON,J.C y PASSERON, C(2005).Le métier de sociologueMouton de Gruyter- Berlin.

BOURDIEU, P (2007). Razones prácticas- Anagrama- Barcelona.

BOUDON, R (1971), Les mathématiques en sociologie -Presses Universitaires de France- Paris.

BOUDON, R (1991), Les méthodes en sociologie -Presses Universitaires de France- Paris.

CORVALÁN, J(2012)."El esquema cruzado como forma de análisis cualitativo en ciencias sociales"-Cinta de Moebio42-Santiago (págs. 243-260).

CORVALÁN, J(2013).“La narrativa educacional chilena y su proceso de transformación reciente: Un análisis sociológico-histórico”.Folios 37- Bogotá (págs 63-81).

CORVALÁN,J y JOIKO,S (2010). "La permanencia de escuelas de bajo desempeño en Chile: investigación cualitativa en seis escuelas de bajo rendimiento crónico en Santiago" accesible en http://biblioteca.uahurtado.cl/ujah/reduc/pdf/pdf/txt128307.pdf (revisado el 28 de mayo 2013)

CORVALÁN, J yROMÁN, M(2012)."La permanencia de escuelas de bajo rendimiento crónico en le cuasi mercado educativo chileno" -Revista Uruguaya de Ciencia Política 21(01)Montevideo(págs43-64).

D'ANDRADE, R. (1995). The Development of Cognitive Anthropology-Cambridge University Press - Cambridge.

DE SAUSSURE F. (1945).Curso de lingüistica general -Losada- Buenos Aires.

GARCÍA-HUIDOBRO J.E (2007).“Desigualdad educativa y segmentación del sistema escolar. Consideraciones a partir del caso chileno"-Pensamiento Educativo 40 - Santiago (págs65-85).

GARCÍA-HUIDOBRO, J.E y CORVALÁN, J(2009)“Obstáculos para el logro de una educación democrática inclusiva”-Perspectivas39 (3)- Ginebra (págs. 239-250).

GREIMAS, A(1971). SemánticaEstructural- Gredos - Madrid.

HIERNAUX, J P (1977).L'Institution Culturelle-Presse Universitaires de Louvain- Louvain. 
HIERNAUX, J P (2008).“Análisis estructural de contenidos. Aplicación a materiales voluminosos"- El sentido y el método- Suárez, H.J (Editor)UNAM- El Colegio de MichoacánMéxico.

HUGHES, J y SHARROCK W, (1999).La filosofía de la investigación social-México - Fondo de Cultura Económica- México

LARRAÍN. J(2010).El concepto de ideología. Vol 4. Posestructuralismo, postmodernismo y postmarxismo- LOM - Santiago

LÉVY-STRAUSS, C. (1974).Anthropologie structurale -Plon - Paris.

MARTINIC, S. 2006. El estudio de las representaciones y el análisis estructural del discurso, en Metodologías de la investigación social. Introducción a los oficios, editado por Canales, M. pp. 299-320. LOM - Santiago.

PIRET, A, NIZET, J, y BOURGEOIS, E (1996). L 'analyse structurale - De Boeck -Bruxelles.

RUQUOY D. (1990).«Les principes et procédés méthodologiques de l'analyse structurale »Méthode d'analyse de contenu et sociologie -Rémy,J y Ruquoy, D (Editores) -Facultés Universitaires Saint-Louis -Bruxelles.

TRUBETZKOY,N(1973). Principios de fonología-Cincel- Madrid

VALENZUELA, J P, BELLEI, C y DE LOS RÍOS, D (2010)“Segregación escolar en Chile” ¿Fin de ciclo? Cambios en la gobernanza del sistema educativo, Martinic, S y Elacqua, G (Editores) UNESCO- Pontifica Universidad Católica de Chile- Santiago. 